\title{
Automated threshold detection for auditory brainstem responses: comparison with visual estimation in a stem cell transplantation study
}

\author{
Sofie Bogaerts ${ }^{1}$, John D Clements ${ }^{2}$, Jeremy M Sullivan ${ }^{1}$ and \\ Sharon Oleskevich*1,2
} \author{
New South Wales, Sydney, Australia \\ Email: Sofie Bogaerts - s.bogaerts@bernhoven.nl; John D Clements - john.clements@axograph.com; \\ Jeremy M Sullivan - j.sullivan@garvan.org.au; Sharon Oleskevich* - s.oleskevich@garvan.org.au \\ * Corresponding author
}

Address: ${ }^{1}$ Neuroscience Research Program, Garvan Institute of Medical Research, Sydney, 2010, Australia and ${ }^{2}$ Faculty of Medicine, University of

Published: 26 August 2009

BMC Neuroscience 2009, 10:104 doi:10.1 186/147/-2202-10-104

This article is available from: http://www.biomedcentral.com//47/-2202/10//04

(C) 2009 Bogaerts et al; licensee BioMed Central Ltd.

This is an Open Access article distributed under the terms of the Creative Commons Attribution License (http://creativecommons.org/licenses/by/2.0), which permits unrestricted use, distribution, and reproduction in any medium, provided the original work is properly cited.

\begin{abstract}
Background: Auditory brainstem responses (ABRs) are used to study auditory acuity in animalbased medical research. ABRs are evoked by acoustic stimuli, and consist of an electrical signal resulting from summated activity in the auditory nerve and brainstem nuclei. ABR analysis determines the sound intensity at which a neural response first appears (hearing threshold). Traditionally, threshold has been assessed by visual estimation of a series of $A B R s$ evoked by different sound intensities. Here we develop an automated threshold detection method that eliminates the variability and subjectivity associated with visual estimation.
\end{abstract}

Results: The automated method is a robust computational procedure that detects the sound level at which the peak amplitude of the evoked $A B R$ signal first exceeds four times the standard deviation of the baseline noise. Implementation of the procedure was achieved by evoking ABRs in response to click and tone stimuli, under normal and experimental conditions (adult stem cell transplantation into cochlea). Automated detection revealed that the threshold shift from pre- to post-surgery hearing levels was similar in mice receiving stem cell transplantation or sham injection for click and tone stimuli. Visual estimation by independent observers corroborated these results but revealed variability in ABR threshold shifts and significance levels for stem cell-transplanted and sham-injected animals.

Conclusion: In summary, the automated detection method avoids the subjectivity of visual analysis and offers a rapid, easily accessible http://axograph.com/source/abr.html approach to measure hearing threshold levels in auditory brainstem response.

\section{Background}

The auditory brainstem response (ABR) is a voltage response evoked by acoustic stimuli as sound is processed along the auditory pathway. It consists of electrical signals resulting from the sum of sound-evoked activity along the auditory nerve and brainstem nuclei. ABR analysis deter- 
mines the sound intensity at which a neural response first appears (hearing threshold) [1]. Previous studies in rats in mice have shown that ABR thresholds do not indicate absolute behavioural hearing thresholds $[2,3]$. However, ABR audiometry has been used extensively in animal hearing research for examining gene therapy [4-10], cellreplacement therapies [11-14], and noise-induced hearing loss [15-20].

The ABR offers an objective measurement of auditory signal processing. The objectivity is diminished by conventional visual inspection of the ABR threshold level. Subjectivity and variability are introduced when the investigator has to decide when a complex, multi-component response first becomes distinguishable from background noise [21]. Methodologies have been developed to address the subjective component of threshold detection by including criteria about the shape, pattern, or absolute amplitude of the response, yet these still require a visual decision about the presence of a signal. Eliminating subjectivity in auditory threshold determination would improve the sensitivity and reliability of this important audiometric technique.

While visual estimation remains the conventional technique for ABR threshold detection, a need for automated statistical methods for detection is highly recognised. Several methods have been developed based on the techniques of $\mathrm{F}_{\mathrm{sp}}$ analysis [22-25], cross correlation [26-28] and feature vectors [29-32]. $\mathrm{F}_{\mathrm{sp}}$ analysis requires calculation of a variance ratio in the ABR waveform followed by application of the F-statistic to this ratio. Cross correlation measures the degree of similarity between a sliding template and an averaged waveform. Feature vectors quantify selected components of the response's time course. $F_{\mathrm{sp}}$ has been incorporated into available software (Compumedics Ltd) yet the other methods lack comparable implementation.

Here we develop a simple, fully automated auditory threshold detection method to address the subjectivity and variability associated with visual estimation of ABRs. This method is based on the signal-to-noise ratio and the software has been made readily available [33]. The algorithm is calibrated by comparison with visual estimation, implemented via investigation of stem cell transplantation, and compared against variability obtained with visual estimation.

\section{Results and discussion Algorithm}

The automated method is based on the ratio between the observed peak amplitude of the evoked ABR signal and the standard deviation (SD) of the baseline noise. The peak was taken as the maximum absolute amplitude of the averaged evoked ABR signal in a time window encompassing the ABR signal (Figure 1). This peak amplitude represents the true peak amplitude plus a contribution from the background noise. The SD of the noise was calculated in a time window clearly following termination of the ABR signal. These calculations were repeated for each member of the family of voltage responses recorded at different sound intensity levels. The median value of the SDs was taken as the best available estimate of the true noise $\mathrm{SD}$. The sound intensity level was deemed to have reached threshold when the peak ABR amplitude was four times the noise SD (Figure 1B). This signal-to-noise ratio was chosen after investigating other values ( $\mathrm{SD}=3$ or 5$)$ as it provides sensitive signal detection while maintaining a low probability of a false positive.

The automated detection method is based on a statistical foundation. Assuming a normal distribution of baseline noise data, $99.98 \%$ of noise values will lie within \pm 4 SD of the mean. Any amplitude values occurring outside this range allow rejection of the null hypothesis (no ABR signal) at the $\mathrm{p}<0.0002$ level. This confidence level is valid when a single data point in the ABR signal is examined. If we search for a peak amplitude across a time window containing 100 data points, then a peak signal $>4$ SD is significantly different from baseline noise at the $\mathrm{p}<0.02$ level, thus confirming the presence of an ABR signal and providing a statistically reliable estimate of the hearing threshold level.
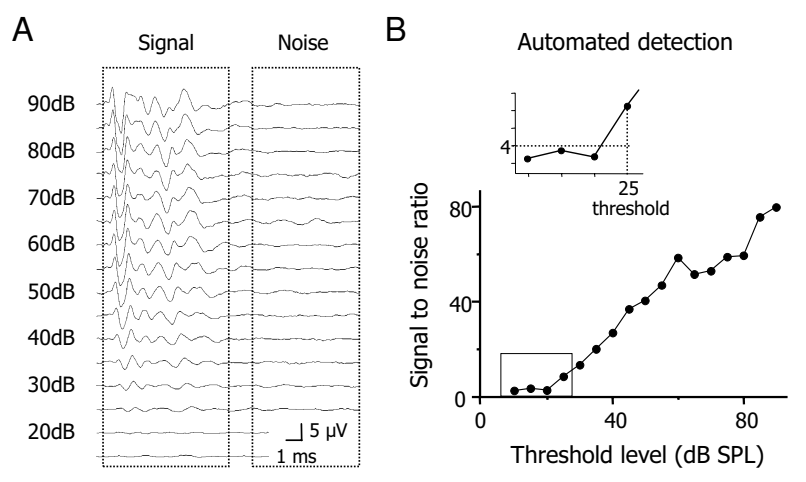

\section{Figure I}

Computational algorithm for ABR threshold detection. A. Series of auditory brainstem responses (ABRs) evoked by click stimuli delivered at decreasing intensities. The automated threshold detection method compares the peak amplitude of the signal versus the standard deviation of baseline noise (boxed areas). B. Plot of the signal-to-noise ratio is used to calculate the hearing threshold level when peak amplitude is four times the standard deviation of the baseline noise to ensure few false positives (inset). 
An automated detection method based on the signal-tonoise ratio has previously been reported $[22,23,25]$. This method requires calculation of a parameter, $\mathrm{F}_{\mathrm{sp}}$, which is the variance of the amplitude values across an specified time window of the averaged response $(\operatorname{VAR}(S))$, divided by the variance of the amplitude of a single time point across several hundred sweeps (VAR(SP)). This deterministic approach assumes that the evoked ABR voltage waveform is constant from trial to trial yet neural population signals typically fluctuate in amplitude from trial to trial due to changes in the number of neurons contributing to the response. Such ABR amplitude fluctuations will cause VAR(SP) to be systematically overestimated. In contrast, assumption of biological variability has been included in our algorithm.

This relatively simple and intuitive threshold detection method was developed as a plug-in module for AxoGraph $\mathrm{X}$, a data analysis application (AxoGraph Scientific). The automated analysis module, with source code, is freely available with an application license [33]. The module imports a graph containing the family of averaged voltage responses recorded at different sound intensity levels, then automatically outputs a plot of the signal-to-noise ratio versus sound intensity, with the ABR threshold level indicated.

\section{Automated method detects accurate and consistent hearing threshold levels}

To test the automated detection method, ABRs were evoked by acoustic stimuli (click and tone) and measured with subdermal electrodes in normal-hearing mice (Figure 1,2$)$. The ABRs consisted of five major wave components as reported previously [34-36]. In mice, the waves likely correspond to peripheral signal processing (wave I; auditory nerve) and central signal processing (waves II-V; cochlear nucleus, superior olivary complex, lateral lemniscus, inferior colliculus, respectively). Acoustic stimuli were delivered in descending intensities and hearing thresholds were detected by computerised automated detection and compared to visual estimations of hearing thresholds. For automated detection, peak signal and background noise measurements were made in time windows of $0.5-8 \mathrm{~ms}$ and $12-20 \mathrm{~ms}$, respectively. A plot of signal-to-noise ratio versus sound intensity level was generated, and the ABR threshold level was indicated (see inset: Figure 1B). For visual estimation, two experienced observers (auditory clinician, neuroscientist) noted the lowest sound intensity that evoked an ABR.

For click and tone stimuli, automated detection produced a similar threshold value as visual estimation for the same series of ABR traces in normal-hearing mice (Figure 2). Summary data indicated that automated detection provided a mean threshold value of $33 \pm 2 \mathrm{~dB}(\mathrm{n}=21)$ for click stimuli that was not significantly different than the
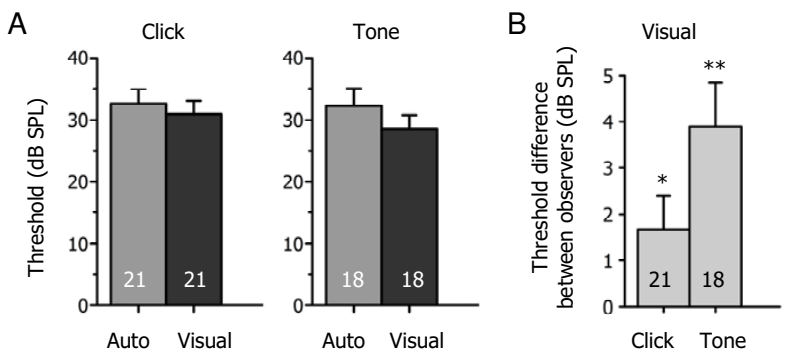

\section{Figure 2}

Automated method detects accurate and consistent hearing threshold levels. A. Summary data showing that automated detection with a signal-to-noise ratio value of four $(\mathrm{SD} \pm 4)$ predicts equivalent and consistent threshold levels in comparison to visual estimation for click and tone (16 $\mathrm{kHz}$ ) stimuli. B. The variability associated with visual estimation is evident as the absolute difference in threshold values between two observers was statistically different than zero for click $(* p<0.05)$ and tone stimuli $(* * p<0.00 I)$. Values expressed as mean \pm SEM for all graphs with number of animals indicated within columns.

mean threshold value predicted by visual estimation (31 $\pm 2 \mathrm{~dB} ; \mathrm{n}=21$; Figure $2 \mathrm{~A}$ ). This was also consistent in response to tone stimuli where automated detection showed a mean threshold value of $32 \pm 3 \mathrm{~dB}(\mathrm{n}=18)$ while visual estimation predicted a mean threshold value of $29 \pm 2 \mathrm{~dB} ; \mathrm{n}=18$; Figure $2 \mathrm{~A}$ ). Individual data revealed that automated detection produced identical estimates of ABR threshold compared to visual estimation in $48 \%$ of mice $(n=10 / 21)$ for click stimuli and in $50 \%$ of mice ( $n$ $=9 / 18$ ) for tone stimuli. In the non-identical data, the threshold estimates for automated detection differed from visual estimation by a mean of $6 \pm 0.6 \mathrm{dBs}(\mathrm{n}=11)$ for click stimuli and by $9 \pm 3 \mathrm{dBs}(\mathrm{n}=9)$ for tone stimuli.

Two independent observers estimated significantly different threshold levels for the same series of ABRs (Figure 2B). The absolute difference in threshold values between observers was statistically different than zero for click stimuli $(1.7 \pm 0.7 \mathrm{~dB} ; \mathrm{n}=21 ; \mathrm{p}<0.05)$ and for tone stimuli $(3.9 \pm 0.9 \mathrm{~dB} ; \mathrm{n}=18 ; \mathrm{p}<0.001)$. Together, the results confirm that a signal-to-noise ratio value of four $(S D \pm 4)$ predicts equivalent and consistent threshold levels in comparison to visual estimation and that variability in threshold detection is associated with visual estimation.

\section{Automated detection method is used to investigate vestibular stem cell transplantation}

The automated threshold algorithm was implemented to investigate the effect of adult stem cell transplantation into the cochlea on hearing threshold levels (Figure 3). Stem cell transplantation is rapidly gaining interest as a potential therapy for hearing loss (for review see $[37,38]$ ). Our recent findings show that transplantation of adult 


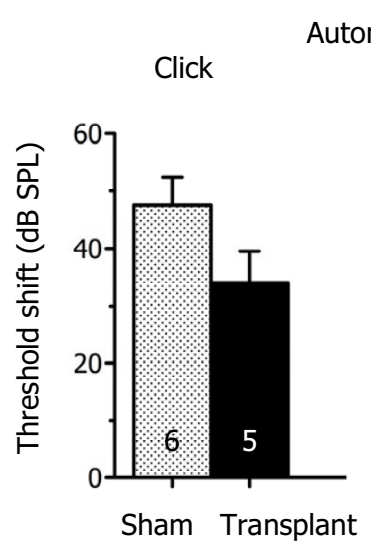

utomated

Tone

Figure 3

Automated detection method is used to investigate vestibular stem cell transplantation. The mean difference in ABRs before and after surgery (threshold shift) was not significantly different for mice transplanted with vestibular stem cells compared to sham-injected mice in response to click and tone stimuli.

tongue stem cells into deafened mice results in a significantly smaller mean ABR threshold shift compared to sham injection [39]. Previous studies suggest that vestibular stem cells reside in the vestibular sensory epithelium, and are pre-programmed to differentiate into vestibular hair cells that share similarities with cochlear hair cells [40-42]. Here we use the automated threshold algorithm to determine ABR changes after adult vestibular cell transplantation. Acoustic deafening prior to transplantation, as performed in our earlier studies, was omitted to investigate the specific effects of stem cells on transplant surgery. Hearing thresholds were measured four weeks after transplantation of a cell suspension containing vestibular stem cells or sham injection of the vehicle (phosphate buffer) alone. Comparisons were made of the shift between preand post-surgery ABR threshold levels in the treated ear (Figure 3).

The mean ABR threshold shift between pre- and post-surgery hearing levels for mice transplanted with vestibular cells was $34 \pm 6 \mathrm{~dB}(\mathrm{n}=5)$ in response to click stimuli. This threshold shift was not significantly different than for mice receiving a sham injection $(48 \pm 5 \mathrm{~dB} ; \mathrm{n}=6)$. For pure tone stimuli, the mean ABR threshold shift was also not significantly different for stem cell-transplanted (33 \pm $9 \mathrm{~dB} ; \mathrm{n}=5)$ versus sham-injected animals $(41 \pm 3 \mathrm{~dB} ; \mathrm{n}=$ 6; Figure 3B).

\section{Automated detection avoids variability associated with visual estimation}

To assess the subjectivity and variability associated with visual estimation of ABR threshold levels (Figure 4), ten independent observers assessed the threshold levels on the ABRs previously analyzed by automated detection (see Figure 3). The observers were blind to the experimental conditions, and included experienced auditory clinicians and neuroscientists. Visual estimation corroborated the results provided by automated detection, showing that threshold shifts between stem cell-transplanted and sham-injected mice were not significantly different in response to click and tone stimuli (Figure 4A). However examination of the data for individual observers shows that while most observers did not detect a significant difference in threshold shifts, some observers noted a signif-

\section{A}
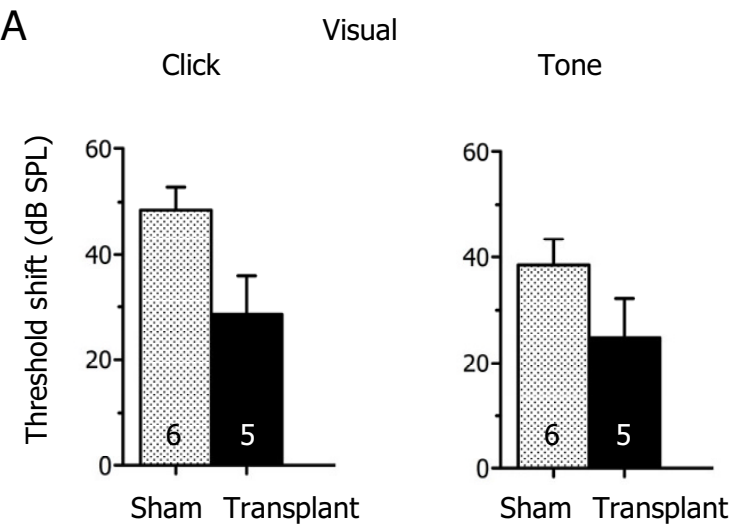

B
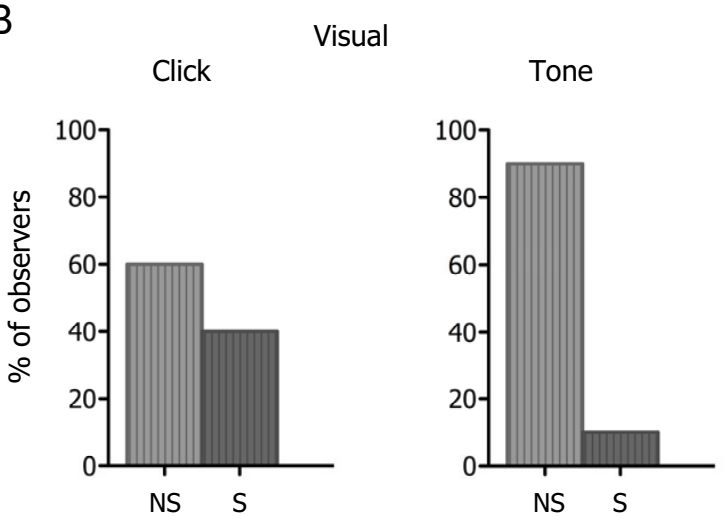

Figure 4

Automated detection avoids variability associated with visual estimation. A. Mean ABR threshold shift for stem cell-transplanted and sham-injected mice in response to click and tone stimuli as estimated by visual inspection. The mean value for each animal was calculated from the data of ten independent observers. Comparisons of the two cohorts reveal similar results as for data analyzed by automated detection (see Figure 3). B. Examination of the data for individual observers shows that most observers did not detect a significant difference between stem cell-transplanted and sham-injected mice (NS) while some observers noted a significant difference in threshold shifts $(S ; p<0.05)$. This variability in significance levels differed between click and tone stimuli. 
icant difference $(\mathrm{p}<0.05)$ between stem cell-transplanted and sham-injected mice (Figure $4 \mathrm{~B}$ ). This variability in significance levels differed for click and tone stimuli. Thus the automated detection method predicts similar mean threshold values as visual estimation, in agreement with the results obtained for normal-hearing mice (Figure 2A), and avoids the variability in ABR threshold shifts and significance levels associated with visual estimation.

\section{Conclusion}

A simple, fully automated auditory threshold detection method was developed to address the subjectivity and variability associated with visual estimation of ABRs. The threshold values provided by automated detection were similar to those provided by visual estimation, indicating the automated method predicts valid threshold levels. The automated detection method was implemented in experimental conditions and revealed no difference between stem cell-transplanted and sham-injected mice. Visual estimation by independent observers corroborated these results but revealed variability in ABR threshold shifts and significance levels for stem cell-transplanted and shaminjected animals. In summary, the automated detection method developed here offers an accessible, accurate, and reproducible approach for measuring hearing threshold levels in auditory brainstem responses.

\section{Methods}

\section{Auditory Brainstem Responses (ABRs)}

Auditory function was assessed by measuring ABR thresholds in CBA/CaH mice aged 4 to 6 postnatal weeks $(\mathrm{n}=$ 41) as previously described [43]. ABR thresholds were recorded in two groups of animals: normal hearing mice $(\mathrm{n}=30)$ and mice receiving a unilateral stem cell transplantation or sham injection into the left cochlea $(n=11)$. Briefly, mice were anaesthetized with ketamine (100 mg/ $\mathrm{kg}$ ) and xylazine $(20 \mathrm{mg} / \mathrm{kg})$, and ABRs were recorded differentially between subdermal platinum electrodes placed at the vertex and lateral to the left cheek with an electrode at the lower back serving as ground. Clicks (1 ms duration, $100 \mathrm{~ms}$ interstimulus interval) and tone pips (16 kHz; 1 $\mathrm{ms}$ rise/fall; $3 \mathrm{~ms}$ duration, $90 \mathrm{~ms}$ interstimulus interval) were delivered via an electrostatic insert speaker and ABRs were obtained by reducing the intensity in $5 \mathrm{~dB}$ steps beginning at $90 \mathrm{~dB}$ (Tucker Davis Technologies). The ABR signal was obtained by time locked averaging with a minimum of 512 averages. ABRs were band passed filtered above $300 \mathrm{~Hz}$ and below $1500 \mathrm{~Hz}$. No stimulus artifact was observed. With ideal recording conditions, a baseline noise of $100-200 \mu \mathrm{V}$ was achieved. ABRs were recorded with BioSig software (Tucker Davis Technologies) and converted to TIFF files for visual estimation in printed format or to ASCII files for automated computer analysis.
All experiments were performed with the approval of the Garvan Institute and St Vincent's Hospital Animal Ethics Committee, in accordance with the Australian Code of Practice for the Care and Use of Animals for Scientific Purposes (National Health and Medical Research Council, 2004).

\section{Stem cell transplantation}

For vestibular primary cell culture, male and female CBA/ $\mathrm{CaH}$ mice ( $\mathrm{n}=5$; aged $10-15$ postnatal days) were anesthetized with $\mathrm{CO}_{2}$ and decapitated. Inner ears were placed in chilled Dulbecco's modified Eagle medium (D-MEM) containing $9.6 \mathrm{mg} / \mathrm{ml}$ HEPES, and the utricular maculae and ampullary cristae carefully dissected. The outer margins of the sensory epithelia were then trimmed away and the tissues processed according to a method adapted from that of Oshima et al. [42]. Tissues were incubated in 0.5 $\mathrm{mg} / \mathrm{ml}$ thermolysin (Sigma) in D-MEM for $30 \mathrm{~min}$ at $37^{\circ} \mathrm{C}$ and then in $0.125 \%$ trypsin in Hank's Balanced Salt Solution for $20 \mathrm{~min}$ at $37^{\circ} \mathrm{C}$. Tissues were washed in Advanced D-MEM/F-12 medium containing $20 \mathrm{mM}$ glutamine and 10\% fetal bovine serum and gently triturated. Dissociated cells were centrifuged at $400 \times \mathrm{g}$ and resuspended in $10 \mathrm{ml}$ Advanced D-MEM/F-12 medium containing $20 \mathrm{mM}$ glutamine, B-27 supplement minus vitamin A, N2 supplement, $20 \mathrm{ng} / \mathrm{ml} \mathrm{EGF,} 20 \mathrm{ng} / \mathrm{ml} \mathrm{bFGF}$ (both Millipore), $100 \mathrm{U} / \mathrm{ml}$ penicillin $\mathrm{G}$ and $100 \mu \mathrm{g} / \mathrm{ml}$ streptomycin. The cell suspension was then poured through a $70 \mu \mathrm{m}$ cell strainer (BD Falcon) into plastic tissue culture dishes (BD Falcon) and cultured at $37^{\circ} \mathrm{C}$ with $5 \% \mathrm{CO}_{2}$. Cells were collected after seven days in vitro for transplantation experiments after dissociation with TrypLE Express. All reagents from Invitrogen unless otherwise stated.

For transplant surgery, cochleostomies were performed on $\mathrm{CBA} / \mathrm{CaH}$ mice aged 4 to 6 postnatal weeks $(\mathrm{n}=11)$ as previously described [43]. Briefly, minimal trauma surgery was performed on mice anaesthetised with $75 \mathrm{mg} / \mathrm{kg}$ ketamine and $15 \mathrm{mg} / \mathrm{kg}$ xylazine. A minimally invasive procedure was initiated by micro drilling through the bulla to access the inner ear and perform a lateral wall cochleostomy in the basal turn of the cochlea. Transplantations were made using a glass capillary needle (tip diameter of $100 \mu \mathrm{m}$ ) inserted into the cochleostomy. For stem cell injections $(n=6)$, one microliter of stem cells suspended in phosphate buffer was injected over one minute to deliver 2000-4000 cells. For sham injections $(n=5)$, identical techniques were followed except that phosphate buffer was substituted for the stem cell solution.

Statistics are quoted as mean \pm standard error of the mean (SEM). Significant differences in mean threshold values 
were determined using a two-tailed unpaired t-test (Prism, GraphPad).

\section{Authors' contributions}

SB recorded auditory brainstem responses, performed transplantation surgery and data analysis, and aided in manuscript preparation. JDC developed the computer software for automated detection and aided in manuscript preparation. JMS prepared vestibular stem cells for transplantation and aided in manuscript preparation. SO participated in design of the study, performed the statistical analysis, and prepared the manuscript. All authors read and approved the final manuscript.

\section{Authors' information}

The authors SB, JMS, and SO have no competing interests; JDC is a software programmer at AxoGraph Scientific.

\section{Acknowledgements}

The authors are grateful to the Australian Deafness Research Foundation and the Fairfax Foundation for research funding.

\section{References}

I. Jewett DL, Williston JS: Auditory-evoked far fields averaged from the scalp of humans. Brain 197I, 94(4):68I-696.

2. Heffner HE, Heffner RS: Audition. In Handbook of Research Methods in Experiemtnal Psychology Edited by: Davis SF. Malden, MA: Blackwell; 2003.

3. Heffner HE, Koay G, Heffner RS: Comparison of behavioral and auditory brainstem response measures of threshold shift in rats exposed to loud sound. J Acoust Soc Am 2008, I 24(2): I093-I I04.

4. Ishimoto S, Kawamoto K, Kanzaki S, Raphael Y: Gene transfer into supporting cells of the organ of Corti. Hear Res 2002, I73(I2): $187-197$.

5. Kawamoto K, Ishimoto S, Minoda R, Brough DE, Raphael Y: Math I gene transfer generates new cochlear hair cells in mature guinea pigs in vivo. J Neurosci 2003, 23(I I):4395-4400.

6. Kawamoto K, Kanzaki S, Yagi M, Stover T, Prieskorn DM, Dolan DF, Miller JM, Raphael Y: Gene-based therapy for inner ear disease. Noise Health 200I, 3(I I):37-47.

7. Kawamoto K, Sha SH, Minoda R, Izumikawa M, Kuriyama H, Schacht J, Raphael Y: Antioxidant gene therapy can protect hearing and hair cells from ototoxicity. Mol Ther 2004, 9(2): 173-181.

8. Kawamoto K, Yagi M, Stover T, Kanzaki S, Raphael Y: Hearing and hair cells are protected by adenoviral gene therapy with TGF-beta I and GDNF. Mol Ther 2003, 7(4):484-492

9. Praetorius M, Baker K, Weich CM, Plinkert PK, Staecker H: Hearing preservation after inner ear gene therapy: the effect of vector and surgical approach. ORL J Otorhinolaryngol Relat Spec 2003, 65(4):2||-2|4.

10. Stover T, Yagi M, Raphael Y: Cochlear gene transfer: round window versus cochleostomy inoculation. Hear Res 1999, I36(I2): $124-130$.

II. Hakuba N, Hata R, Morizane I, Feng G, Shimizu Y, Fujita K, Yoshida T, Sakanaka M, Gyo K: Neural stem cells suppress the hearing threshold shift caused by cochlear ischemia. Neuroreport 2005, I 6( I 4): I545-I549.

12. Hildebrand MS, Dahl HH, Hardman J, Coleman B, Shepherd RK, de Silva MG: Survival of partially differentiated mouse embryonic stem cells in the scala media of the guinea pig cochlea. J Assoc Res Otolaryngol 2005, 6(4):34l-354.

13. Iguchi $F$, Nakagawa T, Tateya I, Endo T, Kim TS, Dong Y, Kita T, Kojima K, Naito Y, Omori K, et al.: Surgical techniques for cell transplantation into the mouse cochlea. Acta Otolaryngol Suppl 2004, 55 I:43-47.

14. Okano T, Nakagawa T, Endo T, Kim TS, Kita T, Tamura T, Matsumoto M, Ohno T, Sakamoto T, Iguchi F, et al.: Engraftment of embryonic stem cell-derived neurons into the cochlear modiolus. Neuroreport 2005, I6(I7):1919-1922.

I5. Davis RR, Newlander JK, Ling X, Cortopassi GA, Krieg EF, Erway LC: Genetic basis for susceptibility to noise-induced hearing loss in mice. Hear Res 200I, I 55(I-2):82-90.

16. Kujawa SG, Liberman MC: Acceleration of age-related hearing loss by early noise exposure: evidence of a misspent youth. Neurosci 2006, 26(7):2II5-2123.

17. Ou HC, Bohne BA, Harding GW: Noise damage in the C57BL/ CBA mouse cochlea. Hear Res 2000, I45(I-2): III-122.

18. Vlajkovic SM, Housley GD, Munoz DJ, Robson SC, Sevigny J, Wang CJ, Thorne PR: Noise exposure induces up-regulation of ectonucleoside triphosphate diphosphohydrolases $I$ and 2 in rat cochlea. Neuroscience 2004, I 26(3):763-773.

19. Wang Y, Hirose K, Liberman MC: Dynamics of noise-induced cellular injury and repair in the mouse cochlea. I Assoc Res Otolaryngol 2002, 3(3):248-268.

20. Willott JF, VandenBosche J, Shimizu T, Ding DL, Salvi R: Effects of exposing gonadectomized and intact C57BL/6J mice to a high-frequency augmented acoustic environment: Auditory brainstem response thresholds and cytocochleograms. Hear Res 2006, 22 I(I-2):73-8I.

21. Vidler M, Parker D: Auditory brainstem response threshold estimation: subjective threshold estimation by experienced clinicians in a computer simulation of a clinical test. Int J Audiol 2004, 43:4I 7-429.

22. Elberling C, Don M: Quality estimation of averaged auditory brainstem responses. Scan Audiol 1984, I3(3): 187-197.

23. Elberling $C$, Don $M$ : Threshold characteristics of the human auditory brain stem response. J Acoust Soc Am 1987, 8I(I): II5-12I.

24. Hyde $M$, Sininger $Y S$, Don $M$ : Objective detection and analysis of auditory brainstem response: an historical perspective. Ear Hear 1998, 19(1):97-113.

25. Sininger YS: Auditory brain stem response for objective measures of hearing. Ear Hear 1993, I 4(I):23-30.

26. Cone-Wesson BK, Hill KG, Liu GB: Auditory brainstem response in tammar wallaby (Macropus eugenii). Hear Res 1997, I05(I2): I19-129.

27. Davey R, McCullagh P, Lightbody G, McAllister G: Auditory brainstem response classification: a hybrid model using time and frequency features. Artif Intell Med 2007, 40(I): I- I4.

28. Ozdamar O, Delgado RE, Eilers RE, Urbano RC: Automated electrophysiologic hearing testing using a threshold-seeking algorithm. I Am Acad Audiol 1994, 5(2):77-88.

29. Acir N, Ozdamar O, Guzelis C: Automatic classification of auditory brainstem responses using SVM-based feature selection algorithm for threshold detection. Eng Appl Artif Intel 2006, 19:209-218

30. Keohane BM, Mason SM, Baguley DM: Clinical evaluation of the vector algorithm for neonatal hearing screening using automated auditory brainstem response. J Laryngol and otology 2004, I | 8(2): | |2-।|16.

31. Mason SM: Automated system for screening hearing using the auditory brainstem response. British journal of audiology 1988 , 22(3):2||-2|3.

32. Sanchez R, Riquenes A, Perez-Abalo M: Automatic detection of auditory brainstem responses using feature vectors. International journal of bio-medical computing 1995, 39(3):287-297.

33. Automated ABR threshold detection [http://axograph.com/
[hem source/abr.html]

34. Galbraith G, Waschek J, Armstrong B, Edmond J, Lopez I, Liu W, Kurtz I: Murine auditory brainstem evoked response: putative two-channel differentiation of peripheral and central neural pathways. J Neurosci Methods 2006, I 53(2):214-220.

35. Henry KR: Auditory brainstem volume-conducted responses: origins in the laboratory mouse. Journal of the American Auditory Society 1979, 4(5): I73-178.

36. Zhou X, Jen PH, Seburn KL, Frankel WN, Zheng QY: Auditory brainstem responses in 10 inbred strains of mice. Brain Res 2006, I091(I): 16-26.

37. Hildebrand MS, Newton SS, Gubbels SP, Sheffield AM, Kochhar A, de Silva MG, Dahl HH, Rose SD, Behlke MA, Smith RJ: Advances in molecular and cellular therapies for hearing loss. Mol Ther 2008, I 6(2):224-236. 
38. Sekiya T, Kojima K, Matsumoto M, Holley MC, Ito J: Rebuilding lost hearing using cell transplantation. Neurosurgery 2007, 60(3):417-433.

39. Pandit S, Cohen M, Sullivan JM, Bogaerts S, Oleskevich S: Stem cell therapy for noise-induced hearing loss in mice. Proc Aust Neuroscience Soc 2009, 19:99.

40. $\mathrm{Li} \mathrm{H}$, Liu H, Heller S: Pluripotent stem cells from the adult mouse inner ear. Nat Med 2003, 9(10):1293-1299.

4I. Martinez-Monedero R, Yi E, Oshima K, Glowatzki E, Edge AS: Differentiation of inner ear stem cells to functional sensory neurons. Developmental neurobiology 2008, 68(5):669-684.

42. Oshima K, Grimm CM, Corrales CE, Senn P, Martinez Monedero R Geleoc GS, Edge A, Holt JR, Heller S: Differential distribution of stem cells in the auditory and vestibular organs of the inner ear. J Assoc Res Otolaryngol 2007, 8(I):|8-31.

43. Bogaerts S, Douglas S, Corlette T, Pau H, Saunders D, McKay S, Oleskevich S: Microsurgical access for cell injection into the mammalian cochlea. J Neurosci Methods 2008, 168(I):156-163.

Publish with Bio Med Central and every scientist can read your work free of charge

"BioMed Central will be the most significant development for disseminating the results of biomedical research in our lifetime. "

Sir Paul Nurse, Cancer Research UK

Your research papers will be:

- available free of charge to the entire biomedical community

- peer reviewed and published immediately upon acceptance

- cited in PubMed and archived on PubMed Central

- yours - you keep the copyright

Submit your manuscript here:

http://www.biomedcentral.com/info/publishing_adv.asp 